\title{
Correction to: Evaluation of Wound Healing Potential of $\beta$-Chitin Hydrogel/Nano Zinc Oxide Composite Bandage
}

Sudheesh Kumar P.T ${ }^{\prime}$ - Vinoth-Kumar Lakshmanan ' - Mincy Raj' • Raja Biswas' • Tamura Hiroshi ${ }^{2}$ Shantikumar V. Nair ' Rangasamy Jayakumar'

Published online: 17 May 2019

(C) Springer Science+Business Media, LLC, part of Springer Nature 2019

\section{Correction to: Pharm Res (2013) 30:523-537.} https://doi.org/ 10.1007/s I 1095-0 I 2-0898-y

In the original manuscript, the platelet activation images of the sample treated groups, Fig. 3c were provided incorrectly. Due to this mistake, we have re-performed the experiments in entire groups and the corrected Fig. 3 is given below.

In the original manuscript, Fig. 7a is incorrect. We rectified this mistake and the corrected Fig. 7 is presented below.

These changes in the figures would not affect the overall conclusion of the whole manuscript. The authors would like to apologize for any inconvenience caused.

Publisher's Note Springer Nature remains neutral with regard to jurisdictional claims in published maps and institutional affiliations.

The online version of the original article can be found at https://doi.org/l 0 . | 007/s | | 095-0 | 2-0898-y

\footnotetext{
Rangasamy Jayakumar

rjayakumar@aims.amrita.edu; jayakumar77@yahoo.com

Amrita Centre for Nanosciences and Molecular Medicine, Amrita Institute of Medical Sciences and Research Centre, Amrita Vishwa Vidyapeetham University, Kochi 68204I, India

2 Faculty of Chemistry, Materials and Bioengineering, Kansai University, Osaka 564-8680, Japan
} 
a

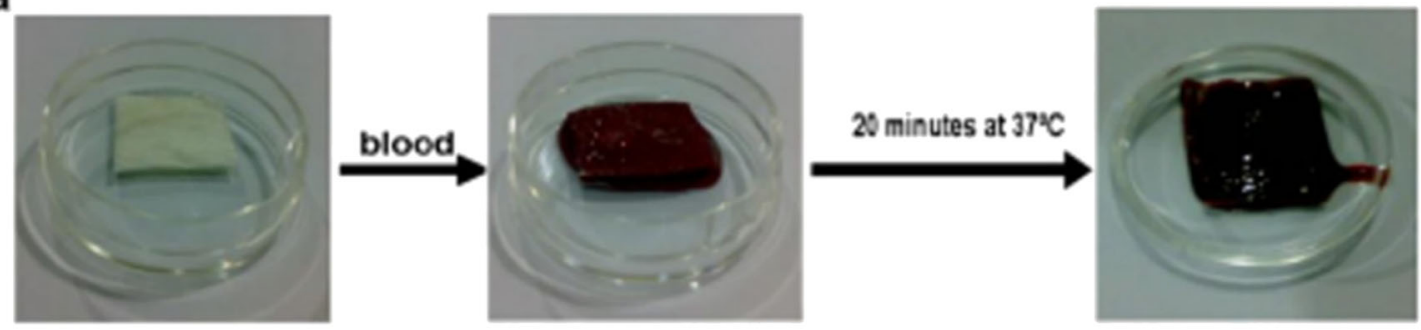

b

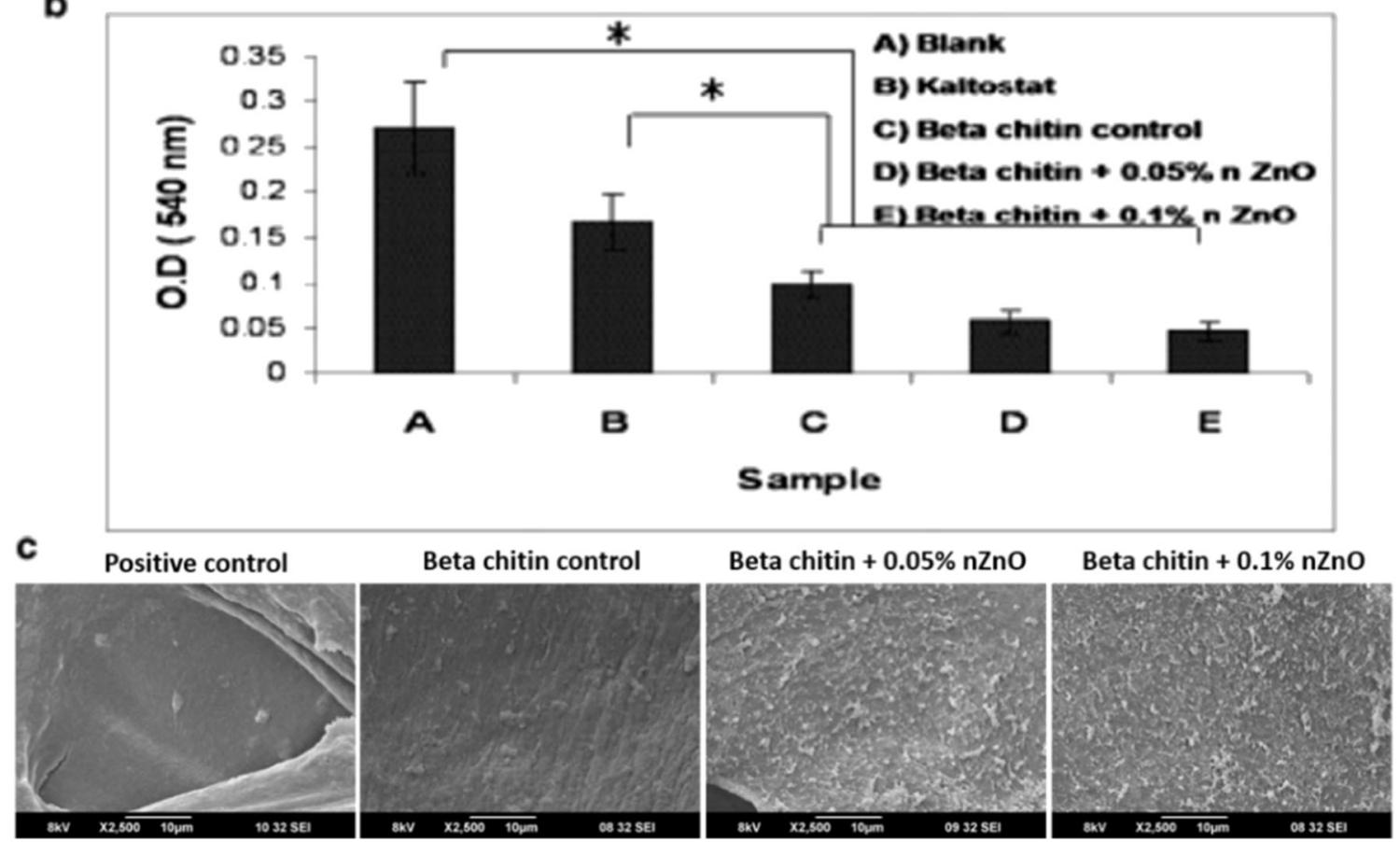

Fig. 3 (a) Photographs of composite bandage, blood on bandage and bandage with blood clot. (b) Blood clotting evaluation of composite bandages. (c) SEM images of platelets attached on the bandages. 
Fig. 7 Laser confocal images of the surface of (a) $\beta$-chitin, (d) $\beta$-chitin $+0.01 \% \mathrm{nZnO}$ and $(\mathbf{g}) \beta$-chitin $+0.1 \% \mathrm{nZnO}$ bandage. Phalloidin dye stained confocal images of the HDF cells attached on (b) $\beta$-chitin, (e) $\beta$-chitin $+0.01 \% \mathrm{nZnO}$ and (h) $\beta$-chitin $+0.1 \% \mathrm{nZnO}$ bandage. Merged confocal images of $(\mathbf{c}) \beta$ chitin, (f) $\beta$-chitin $+0.01 \% \mathrm{nZnO}$ and (i) $\beta$-chitin $+0.1 \% \mathrm{nZnO}$ bandage. Z-stacked laser confocal images of the surface of (j) $\beta$-chitin, (m) $\beta$-chitin $+0.01 \% \mathrm{nZnO}$ and (p) $\beta$-chitin $+0.1 \% \mathrm{nZnO}$

bandage. Phalloidin dye stained Zstacked confocal images of the HDF cells attached on (k) $\beta$-chitin, (n) $\beta$ chitin $+0.01 \% \mathrm{nZnO}$ and (q) $\beta$ chitin $+0.1 \% \mathrm{nZnO}$ bandage. Merged Z-stacked confocal images of (I) $\beta$-chitin, (o) $\beta$-chitin $+0.01 \%$ $\mathrm{nZnO}$ and $(\mathbf{r}) \beta$-chitin $+0.1 \%$ $\mathrm{nZnO}$ bandage (scale represents $200 \mu \mathrm{m})$
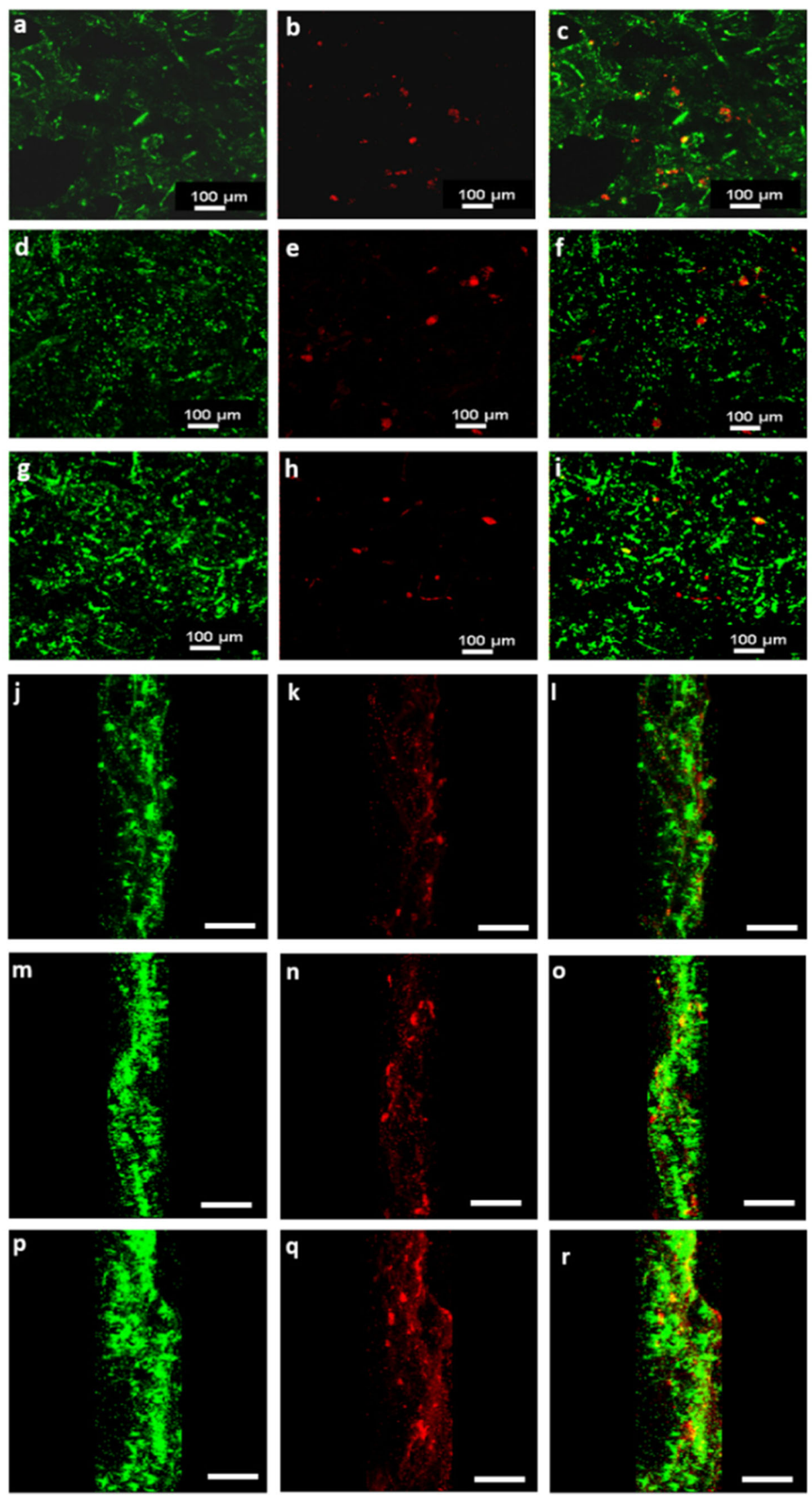